\title{
1 Immunological Patterns from Four Melioidosis Cases: Constant and Variable Protein
}

\section{Antigens}

$4 \quad$ Jinhee $\mathrm{Yi}^{1}$

$5 \quad$ Kelsey Herring ${ }^{1}$

6 Timothy C. Sanchez ${ }^{2}$

7 Srinivas Iyer $^{2}$

8 Joshua K. Stone ${ }^{1}$

9 Judy Lee ${ }^{1}$

10 Mark Mayo $^{3}$

11 Bart J. Currie ${ }^{3}$

12 Apichai Tuanyok ${ }^{1,4}$

13 Paul Keim ${ }^{*}$

14

$15{ }^{1}$ Department of Biological Sciences, Northern Arizona University, Flagstaff, AZ, USA, 86011

$16 \quad{ }^{2}$ Los Alamos National Laboratory, Los Alamos, NM, USA, 87545

$17 \quad{ }^{3}$ Menzies School of Health Research and Infectious Diseases Department, Royal Darwin

18 Hospital, Darwin, Northern Territory

$19{ }^{4}$ Department of Infectious Diseases and Pathology, University of Florida, Gainesville, FL, USA,

$20 \quad 32608$

$21 *$ Corresponding Author

22 E-mail address: Paul.Keim@nau.edu 


\section{Abstract}

Burkholderia pseudomallei is the causative agent of the melioidosis and is endemic to

Southeast Asia and northern Australia. There is no available vaccine and accurate diagnosis is difficult, time-consuming and labor intensive. Early diagnosis is an important part of successful treatment and current serological tests are inadequate and based upon multiple antigens.

34 a specific gene by mass-spectrometry. Results from the Western blotting of each strain's proteins and the corresponding patient serum reveal between $30-40 \%$ serum x strain specific immunogenic proteins. In most cases, these differences exist despite the fact that the genes

37 encoding these proteins were present among all four B. pseudomallei strains. Eight particular proteins were immunogenic in all four strain x serum combinations and could represent novel diagnostic and vaccine subunit targets.

\section{Introduction}

43 causative agent of melioidosis, a potentially deadly disease endemic to Southeast Asia and

44 northern Australia [1]. It is now being recognized in more diverse global regions such as South

45 America, the Caribbean and Africa [1-3]. Melioidosis can manifest in numerous clinical forms, 
most commonly as pneumonia, but also a spectrum from localized cutaneous disease without

47 sepsis to rapidly progressive fatal septicemia [1, 4]. Risk factors have been identified which contribute to the likelihood of developing melioidosis. Diabetes mellitus, hazardous alcohol use, renal disease, chronic pulmonary disease, immunosuppressive therapy and thalassemia are all associated with an increased risk for melioidosis. The mechanism by which these risk factors impact the disease is not entirely clear, but having any of them can result in more severe disease with higher mortality $[1,5]$.

First-line treatment for melioidosis utilizes $\beta$-lactam antibiotics such as ceftazidime, but

54 B. pseudomallei can develop resistance to these antibiotics during the course of acute infection

55 and eradication phases $[6,7]$. This acquired resistance may be linked to efflux pumps, enzymatic

56 inactivation, and alteration of drug targets and decreased permeability [8].

B. pseudomallei is a resilient bacterium that can tolerate hostile conditions by producing and secreting proteases, lipases, catalases, peroxidase and siderophores. In addition, it can evade host immune responses and is able to survive within phagocytic cells [9]. B. pseudomallei produces virulence effectors that can be transferred into host cells through different machineries.

61 For instances, the type III and VI secretion systems have been identified as allowing the bacteria 62 to survive intracellularly, escape autophagy and spread within the host [10-12]. antigens that are recognized by host response antibodies [13]. Such surface antigens are critical targets of humoral immune response and have the potential to be developed for immunological diagnosis and therapies [14]. However, to facilitate the development of better diagnostics,

67 comprehensive information of these antigens is needed. Identifying such proteins in $B$.

68 pseudomallei can form the basis for all these purposes. In this study we determined the 
immunogenic protein profiles in four B. pseudomallei strains which were isolated from four different human melioidosis cases using 2D gel electrophoresis, Western blot hybridization, and mass-spectrometry. The immunogenic protein profiles for all four strains were determined using matched sera from the infected patients.

\section{Materials and Methods}

\section{Ethics Statement}

Our study examined two primary B. pseudomallei isolates (MSHR) obtained from 556 melioidosis patient group from the Darwin Prospective Melioidosis Study, which commenced at Royal Darwin Hospital, Northern Territory, Australia in October 1989. Ethics approval for this study was obtained through the Human Research Ethics Committee of the Northern Territory Department of Health and Menzies School of Health Research, approval number HREC 02/38 (Clinical and Epidemiological Features of Melioidosis) with written informed consent obtained from patients. All patient data were de-identified prior to analysis. The two Arizona USA patients' specimens $(\mathrm{PB})$ were collected for clinical diagnostic purposes and deidentified prior to transfer to NAU. As such, they are exempt from USA IRB regulations.

\section{Bacterial Strains and Growth Conditions}

Four human clinical B. pseudomallei strains MSHR1079, MSHR1328, PB08298010, and PB1007001 were used in this study. Three strains were isolated from blood culture - negative localized infection (e.g., skin, lungs), while the other one was from a blood culture positive case. Details of these strains, sera and clinical information are shown in Table 1. We used Luria- 
bioRxiv preprint doi: https://doi.org/10.1101/082057; this version posted November 20, 2016. The copyright holder for this preprint (which was not certified by peer review) is the author/funder. All rights reserved. No reuse allowed without permission.

93 Bertani (LB) agar to grow the bacterial strains at $37^{\circ} \mathrm{C}$ for 48 hours subjected to protein

94 extraction.

95 
Table 1. Summary of Burkholderia pseudomallei strains and human patient serum used in this study.

\begin{tabular}{|c|c|c|}
\hline $\begin{array}{l}\text { Strain/ LPS } \\
\text { genotype }\end{array}$ & $\begin{array}{l}\text { Country } \\
\text { of origin }\end{array}$ & Sera and Clinical information \\
\hline $\begin{array}{l}\text { MSHR1079/ } \\
\text { serotype B }\end{array}$ & Australia & $\begin{array}{l}\text { This was a } 50 \text { year old patient who was sick for } 6 \text { weeks before the diagnosis of blood } \\
\text { culture-negative skin infection by culture of } B \text {. pseudomallei from the regional lymph node. } \\
\text { Clinical manifestation was an arm abscess with lymph node involvement. IHA titer was very } \\
\text { high on admission (1:5120). The serum was collected from when the treatment was started, } \\
\text { i.e., at the time of initial diagnosis. The patient was treated initially with intravenous } \\
\text { ceftazidime plus oral trimethoprim/sulfamethoxazole and made a full recovery (Tuanyok et } \\
\text { al.[15]). }\end{array}$ \\
\hline $\begin{array}{l}\text { MSHR1328/ } \\
\text { serotype A }\end{array}$ & Australia & $\begin{array}{l}\text { This was a } 29 \text { year old diabetic who was sick for } 2 \text { weeks with mild symptoms before the } \\
\text { diagnosis of blood culture-negative pneumonia. Only sputum was culture positive. IHA titre } \\
\text { was very high on admission }(>1: 5120) \text {. The serum was collected from when treatment was } \\
\text { started, i.e., at the time of initial diagnosis. The patient was treated initially with ceftazidime } \\
\text { and made a full recovery (Tuanyok et al. [15]). }\end{array}$ \\
\hline $\begin{array}{l}\text { PB08298010/ } \\
\text { serotype A }\end{array}$ & $\begin{array}{l}\text { Arizona, } \\
\text { USA }\end{array}$ & $\begin{array}{l}\text { This was a } 32 \text { year old man who was sick for } 6 \text { weeks with a history of type II diabetes, } \\
\text { hypertension, and obesity. Synovial fluid, blood and sputum were culture positive. Clinical } \\
\text { manifestations were severe right knee pain and febrile upon hospital admission but the } \\
\text { patient's hospital course was complicated by respiratory failure that required intubation and } \\
\text { ventilation, acute renal failure, pneumothorax and pneumoperitoneum, anemia and } \\
\text { hypotension. Antibiotics treatment included with meropenem, moxifloxacin, vancomycin, } \\
\text { ceftazidime, gentamicin, and trimethoprim/sulfamethoxazole. All cultures were negative } 2 \\
\text { weeks before discharged from hospital. The serum was collected } 7 \text { weeks after discharged } \\
\text { from hospital. Source of exposure is unknown (Stewart et al. [16]). }\end{array}$ \\
\hline $\begin{array}{c}\text { PB1007001/ } \\
\text { serotype A }\end{array}$ & $\begin{array}{l}\text { Arizona, } \\
\text { USA }\end{array}$ & $\begin{array}{l}\text { This was a } 49 \text { year old woman who was sick for } 8 \text { weeks with a leg skin abscess and a } \\
\text { swollen regional lymph node. Skin abscess fluid was culture positive for B. pseudomallei. } \\
\text { Before diagnosis treatment included clindamycin, imipenem, vancomycin and metronidazole. } \\
\text { The patient was treated with intravenous ceftazidime and oral } \\
\text { trimethoprim/sulfamethoxazole. The time of serum collection is unknown. The } \\
\text { epidemiologic investigation revealed that the patient had traveled to Costa Rica three months } \\
\text { before the patient developed symptoms, suggesting infection acquired overseas. }\end{array}$ \\
\hline
\end{tabular}




\section{Protein Extraction}

For each protein preparation, bacterial colonies were suspended in sterile $1 \mathrm{X} \mathrm{PBS}, \mathrm{pH}$

100

101

102

103

104

105

106

107

108

109

110

111

112

113

114

115

116

117

118

119

7.3 , until a turbidity of 1.5 at $\mathrm{OD}_{600}$ was obtained. The bacterial cells were pelleted by

centrifugation at $16,000 \times \mathrm{g}$ for 3 minutes. The supernatant was removed and the cell pellet was resuspended in $500 \mu \mathrm{L}$ of lysis buffer $(0.5 \%$ Triton $\mathrm{X}-100 ; 50 \mathrm{mM}$ potassium phosphate, $\mathrm{pH} 7.8$; $400 \mathrm{mM} \mathrm{NaCl} ; 100 \mathrm{mM} \mathrm{KCl}$; and $10 \mathrm{mM}$ imidazole). The solution was subjected to 3 freeze \& thaw cycles alternately in liquid nitrogen and a $42^{\circ} \mathrm{C}$ dry bath to lyse the cells. The sample was then centrifuged at $18,000 \times \mathrm{g}$ for 15 minutes at $4{ }^{\circ} \mathrm{C}$ to separate the soluble (liquid) from the insoluble (pellet) proteins

The quantity of each protein sample was determined using the Bradford assay with slight modifications [17]. Bovine serum albumin (Bio-Rad, Hercules, CA, USA) was used as a standard protein. Prior to protein quantification, the sample was rinsed and equilibrated in Tris$\mathrm{HCl}$ buffer.

\section{Two-dimensional electrophoresis (2DE)}

First dimensional isoelectric focusing (IEF) and second dimensional SDS-PAGE were performed as previously described [18-20]. The IEF was conducted in the $\mathrm{pH} 4-7$ range after exploring a wider range ( $\mathrm{pH} 3-10)$ that provided little additional resolution. Most proteins were found to have a pI value between 4.5 and 6.5 and a molecular weight of 20 to $100 \mathrm{kDa}$. Each protein sample was treated with trichloroacetic acid (TCA) and acetone for purification. A total of $100 \mu \mathrm{g}$ of each protein sample was tested on each 2DE. The pellet was resuspended in $160 \mu \mathrm{L}$ of a resuspension buffer. 
The IEF was performed using 2D Electrophoresis ZOOM® IPGRunner System

121

122

123

124

125

126

127

128

129

130

131

132

133

134

135

136

137

138

139

140

141

142

143

(LifeTech, Carlsbad, CA, USA). Briefly, a 7cm IPG strip, pH 4-7, was loaded with $160 \mu \mathrm{L}$ of

the protein sample, and then operated at 6,000 VHr. The IPG strip was treated with the reduction

buffer (130 mM DTT, $5 \mathrm{M}$ urea, and $0.8 \mathrm{M}$ thiourea).for 20 minutes and with an alkylation

buffer (130 mM iodoacetamide, $0.002 \%$ bromophenol blue, $5 \mathrm{M}$ urea, and $0.8 \mathrm{M}$ thiourea).

Proteins immobilized on the IPG strips were further separated using SDS-PAGE with a 4-20\%

Tris-glycine gradient gel (ZOOM® Novex gel, LifeTech). Electrophoresis was performed at 110

V for 90 min, and the gel was then visualized by silver staining according to Shevchenko's

method [21]. Gel image was digitalized by UVP gel documentation system and analyzed using

the VisionWork LS (UVP, Upland, CA, USA).

\section{Western blotting analysis}

A duplicated non-silver stained 2D gel was blotted transferred to a nitrocellulose membrane in a dry transfer system (iBlot@ Dry Blotting system, LifeTech) for 10 minutes at $25 \mathrm{~mA}$. The blotted membrane was blocked with $2.5 \%$ skim milk in $1 \mathrm{X}$ PBS for 1 hour. The membrane was incubated with the patient serum solution $(1: 1,000 \mathrm{v} / \mathrm{v}$ in $2.5 \%$ skim milk) for 1 hour and then washed in $1 \mathrm{X}$ PBS three times. The membrane was incubated with a 1:1,000 dilution of HRP-conjugated goat anti-human IgG secondary antibody (Promega, Madison, WI, USA) in $2.5 \%$ skim milk followed by an additional three washes in PBS. Then, the immunogenic protein spots were developed colorimetrically using 3,3'-Diaminobenzidine solution.

\section{In-Gel Trypsin Digest}

The immunogenic protein spots on the Western blot membrane were matched with 2D silver stained gel image using 2D analysis software (Melanie v. 7.0.6, Genebio, Geneva, $\mathrm{CH}$ ). 
144 The matched immunogenic spots were excised from the gels and destained with $0.02 \%$ sodium

145

146

147

148

149

150

151

152

153

154

155

156

157

158

159

160

161

162

163

164

165

166 thiosulphate and $0.5 \%$ potassium ferricyanide based on the method of Shevchenko et al., (1996). Excised gel pieces were washed and dried with 50\% acetonitrile and then reduced and alkylated in $10 \mathrm{mM}$ DTT and $100 \mathrm{mM}$ iodoacetamide. Proteins were digested in-gel overnight with 12.5 $\mathrm{ng} / \mathrm{mL}$ trypsin (Promega Inc., USA) made up in digestion buffer (50 mM ammonium bicarbonate; $5 \mathrm{mM}$ calcium chloride) at $37^{\circ} \mathrm{C}$. The cleaved peptides were extracted using extraction buffer made up of 5\% formic acid and 50\% acetonitrile. The extraction of digested peptide was facilitated by vortexing for 30 minutes and sonication for 20 minutes. The extracts were placed in new tubes and dried completely [21,22].

\section{Matrix Assisted Laser Desorption/Ionization Time-of-Flight Mass}

\section{Spectrometry (MALDI-TOF MS)}

The dried peptide samples were reconstituted in $4 \mu \mathrm{L}$ of $0.1 \%$ Trifluoroacetic acid (TFA) in water. Samples were mixed 3:1 ratio (matrix:sample) with $5 \mathrm{mg} / \mathrm{mL}$ of Ultrapure $\alpha$-cyano-4hydroxycinnamic acid (CHCA) matrix (Protea, Morgantown, West Virginia). Prior to sample analysis, the mass spectrometer was externally calibrated with a TOF/TOF Calibration peptide mixture of des-Arg-Bradykinin $(1.0 \mathrm{pmol} / \mu \mathrm{L})$, Angiotensin I $(2.0 \mathrm{pmol} / \mathrm{ul}$, Glu-Fibrinopeptide B (1.3 pmol/ $\mu \mathrm{L})$, and adrenocorticotropic hormone (ACTH), (1-17 clip-2.0 pmol/ $\mu \mathrm{L}),(18-39$ clip1.5pmol $/ \mu \mathrm{L}),(7-38 \mathrm{clip}-3.0 \mathrm{pmol} / \mu \mathrm{L}$ ). The 4800 Plus MALDI TOF/TOF Analyzer (ABSciex, Foster City, CA, USA) was used in positive reflector mode. Data were collected in an automated Batch mode utilizing random sampling over the entire sample spot. The mass spectrometer is equipped with a 200-Hz frequency Nd:YAG laser, operating at a wavelength of $355 \mathrm{~nm}$. Twenty-

five sub-spectra for each of 25 randomized positions within the spot $(625 \mathrm{spectra} / \mathrm{spot})$ were 
167 collected in MS-TOF mode and presented as one main spectrum. MS/MS, fragmentation mode,

16850 sub-spectra for each of 13 randomized positions within the spot $(650 \mathrm{spectra} / \mathrm{spot})$. Fixed

169 laser intensity in MS-TOF reflector positive mode, 3600 (arbitrary units), final detector voltage

170 set at $1.883 \mathrm{KV}$. MS/MS-TOF/TOF, Fragmentation mode, fixed laser intensity set at 4500

171 (Arbitrary units), final detector voltage set at $2.080 \mathrm{KV}$. Spectral Mass range 850-4000 m/z,

172 focus mass $2250 \mathrm{~m} / \mathrm{z}$. The MS/MS data were analyzed using the Paragon Algorithm [23] of

173 ProteinPilot Software version 4.0 with settings: Sample type: Identification; Cys Alkylation:

174 Iodoacetamide; Digestion: Trypsin; Instrument: 4800; Species: (no filter applied); Special

175 factors: Gel-based ID; Search Effort: Thorough; ID focus: none applied; Database: Specific

176 strain-translated genome database; and the Detected Protein Threshold: (10\% confidence).

177 Peptide mass and fragmentation spectra were searched against a protein database which was

178 generated from each strain by whole genome sequencing and RAST annotation [24].

\section{Bioinformatic analysis of immunogenic proteins}

Identification of immunogenic proteins was accomplished by determining peptide 


\section{Protein Identification}

192

For proteomic information on identified immunogenic proteins, several web-based tools were used. Cellular location of identified proteins was predicted using the program "PSORTdb" version 2.0 [26]. The presence of signal peptides was inferred using "SignalP" version 4.0 [27]. This program was used to hypothesize $\mathrm{N}$-terminal secretory signal peptides of the identified immunogenic proteins. Proteins with a SignalP D-score $>0.57$ were considered to be potentially translocated. Protein identity was analyzed using BLASTP against our RAST-generated database. Theoretical molecular weight and pI values were calculated using Compute I/Mw tool on ExPASy website (http://web.expasy.org/compute_pi/).

\section{Results}

\section{Experimental design and serum selection}

Because of the great genomic diversity among B. pseudomallei strains [28], we used matched sets of human sera and protein extracts of isolates from these same melioidosis patient (Table 1). This was done to insure that at least the genes for antigenic proteins are present with the potential to express and to be detected by the host. In one preliminary experiment, we did examine the antigenicity of proteins expressed in vitro from a single strain (PB08298010) against sera from its source patient but also two others (PB08298010 and MSHR1328). We found that the two heterologous cross-reaction Western blots detected fewer immunogenic proteins than its source patient's serum (data not presented). This is consistent with differential strain gene 
212 contents, but it should also be noted that each melioidosis case is unique with a different host,

213 infection time sequences and complex pathologies that could alter antigen-humoral responses.

\section{Immunogenic protein profiles}

melioidosis cases (Fig 1). The cross reactivity of these 135 proteins was distributed in a complex

Fifty unique proteins were identified using MS and ascribed to specific genes (Table 2).

228 commonly detected in all the four strains.

\section{Comparison of identified common immunogenic proteins}



247 closely related bacteria.

common immunogenic proteins to be used as a diagnostic biomarker or vaccine target candidate. For protein sequence BLAST, the sequence of Staphylococcus aureus NCTC8325, Clostridium perfringens F262, Lactobacillus acidophilus ATCC 4796, Escherichia coli MG1655, Burkholderia mallei ATCC 23344, and B. thailandensis E264 were used. The BLAST results showed there were low similarities with the four selected commensal bacteria. Most similarities were less than $50 \%$ and even the highest similarity of GroEL and EF-Tu showed only $76 \%$ and $80 \%$, respectively, with the commensal bacteria. There are likely unique epitopes in the $B$. pseudomallei proteins that would not be confounded by infections by these or related bacteria. As would be expected, the sequence similarity of $B$. mallei and B. thailandensis was higher with an almost $100 \%$ similarity. However, Ndh and AtoC proteins of non-pathogenic B. thailandensis E264 showed a relatively lower similarity than B. mallei ATCC23344 as evidenced by $93 \%$ and 94\% respectively. This illustrates the complications for diagnostics in distinguish infections by

Figure 1: 2D silver stained map of immunogenic proteins of four Burkholderia pseudomallei strains. Colored circles highlight all immunogenic proteins identified. Proteins identified in at least two strains as immunogenic are colored in yellow and in only one strain as follows: MSHR1079 (blue), MSHR1328 (orange), PB08298010 (purple), and PB1007001 (green).

\section{Figure 2: Comparison of immunogenic proteins identified from four Burkholderia} pseudomallei strains. Number is the total detected immunogenic protein spots for each strain and numbers in parentheses are the number of identified immunogenic protein spots for each strain by mass spectrometry. Colored circles correspond to each strain as follows: MSHR1079 (blue), MSHR1328 (orange), PB08298010 (purple), and PB1007001 (green). Note: This 2DE image was generated from B. pseudomallei strain PB0829010. 
Table 2. Immunoreactive proteins identified from four Burkholderia pseudomallei strains

\begin{tabular}{|c|c|c|c|c|c|c|c|c|}
\hline $\begin{array}{c}\text { Spot } \\
\text { number }\end{array}$ & Functional Category (RAST classification) / Protein & Gi \# & $\begin{array}{c}\text { MSHR } \\
1079\end{array}$ & $\begin{array}{c}\text { MSHR } \\
1328\end{array}$ & PB08 & PB10 & $\begin{array}{l}\text { Classification } \\
\qquad(\mathrm{KEGG})^{\mathrm{b}}\end{array}$ & Locus Tag \\
\hline & Amino acids and Derivatives & & & & & & & \\
\hline 96 & 2-isopropylmalate synthase (EC 2.3.3.13) ${ }^{\mathrm{C}}$ & gi|53718837 & + & & & + & K01649 & BPSL1201 \\
\hline 77 & Arginine deiminase (EC 3.5.3.6) & gi|53719357 & & & + & & K01478 & BPSL1743 \\
\hline 58 & Argininosuccinate synthase (EC 6.3.4.5) & gi|53719335 & & & + & & K01940 & BPSL1721 \\
\hline 30 & $\begin{array}{l}\text { Branched-chain alpha-keto acid dehydrogenase, E1 component, beta } \\
\text { subunit (EC 1.2.4.4) }\end{array}$ & gi| 53723290 & & + & + & & K00167 & BPSS2272 \\
\hline 25 & Electron transfer flavoprotein, alpha subunit & gi|53720108 & & + & & + & K03522 & BPSL2499 \\
\hline 59 & Isovaleryl-CoA dehydrogenase (EC 1.3.99.10) & gi|53722471 & & & & + & K00253 & BPSS1448 \\
\hline 45 & Phenylacetate-CoA oxygenase/reductase, PaaK subunit & gi|53720842 & & + & + & & K02613 & BPSL3234 \\
\hline \multirow[t]{2}{*}{75} & Seryl-tRNA synthetase (EC 6.1.1.11) & gi|53720210 & & & + & & K01875 & BPSL2600 \\
\hline & Carbohydrate & & & & & & & \\
\hline 118 & $\begin{array}{l}\text { Dihydrolipoamide dehydrogenase of pyruvate dehydrogenase } \\
\text { complex (EC 1.8.1.4) }\end{array}$ & gi|53719909 & & + & + & + & K00382 & BPSL2299 \\
\hline 74 & Dihydrolipoamide succinyltransferase component (E2) (EC 2.3.1.61) & gi|126452386 & & & + & & K00658 & BPSL1908 \\
\hline 47 & Enolase (EC 4.2.1.11) & gi|53719880 & + & + & + & + & K01689 & BPSL2270 \\
\hline 18 & Methylisocitrate lyase (EC 4.1.3.30) & gi|53721241 & + & & & & K03417 & BPSS0206 \\
\hline 78 & Phosphate acetyltransferase (EC 2.3.1.8) & gi|53722976 & + & + & & & K00625 & BPSS1955 \\
\hline 70 & phosphoglucomutase/phosphomannomutase family protein & gi|53720276 & & & + & & K15778 & BPSL2666 \\
\hline 127 & Succinate dehydrogenase flavoprotein subunit (EC 1.3.99.1) & gi|53722739 & + & & & & K00239 & BPSS1718 \\
\hline \multirow[t]{2}{*}{95} & Sucrose-6-phosphate hydrolase (EC 3.2.1.26) & gi|53721578 & + & & & & K01212 & BPSS0542 \\
\hline & Cell division and cell cycle & & & & & & & \\
\hline 39 & Cell division protein FtsA & gi|53720631 & + & + & + & + & K03590 & BPSL3021 \\
\hline \multirow[t]{2}{*}{$83 / 92$} & Cell division trigger factor (EC 5.2.1.8) & gi|53719038 & + & & + & + & K03545 & BPSL1402 \\
\hline & DNA metabolism & & & & & & & \\
\hline 42 & RecA Protein & gi|53718415 & & + & + & & K03553 & BPSL0776 \\
\hline
\end{tabular}




\section{Membrane Transport}

63 Autotransporter adhesin

Carboxypeptidase C (Cathepsin A)

gi|53720315

gi|53720325

lipoprotein, VacJ family

gi|53720754

BPSL2705

BPSL2715

BPSL3147

\section{Metabolism of aromatic compound}

122/13 Aldehyde dehydrogenase (EC 1.2.1.3), PaaZ

gi|53720650

$$
+
$$

gi|162210084

$+$

K02406

BPSL3319

Flagellar biosynthesis protein FliC

\section{Protein metabolism}

\section{Translation elongation factor Tu}

Translation initiation factor 2

\section{Regulation and Cell signaling}

24

61

82

LysR-family transcriptional regulator

Probable transcription regulator protein of MDR efflux pump cluster

Sigma-54 dependent DNA-binding response regulator

\section{RNA metabolism}

\begin{tabular}{|c|c|c|c|c|c|c|}
\hline gi|53719040 & & & + & + & K03544 & BPSL1404 \\
\hline gi|53720436 & + & & & + & K04043 & BPSL2827 \\
\hline gi|53718723 & & + & + & + & K04079 & BPSL1087 \\
\hline gi|53720307 & + & + & + & + & K04077 & BPSL2697 \\
\hline gi|53720087 & & & + & & K03592 & BPSL2478 \\
\hline gi|53720823 & + & + & + & + & K02358 & BPSL3215 \\
\hline gi|126455003 & & & + & & K02519 & BPSL1918 \\
\hline
\end{tabular}

\begin{tabular}{|c|c|c|c|c|c|c|}
\hline gi|685701990 & + & + & + & + & / & BPSL0841 \\
\hline gi|53718371 & & & & + & / & BPSL0731 \\
\hline gi|403079328 & + & + & + & + & / & BPSL2475 \\
\hline
\end{tabular}




\section{Respiration}

76 ATP synthase alpha chain (EC 3.6.3.14)

71/72 ATP synthase beta chain (EC 3.6.3.14)

$46 \quad$ NADH dehydrogenase (EC 1.6.99.3)

\begin{tabular}{|c|c|c|c|c|c|c|}
\hline gi|53721005 & + & & & & K02111 & BPSL3398 \\
\hline gi|53721003 & & & + & + & K02112 & BPSL3396 \\
\hline gi|53722790 & + & + & + & + & K03885 & BPSS1769 \\
\hline
\end{tabular}

\section{Sulfur metabolism}

$4 \quad$ Thiol peroxidase, Tpx-type (EC 1.11.1.15)

\section{Stress response}

5/6/7 Alkyl hydroperoxide reductase protein C (EC 1.6.4.-)

12 Alkyl hydroperoxide reductase subunit C-like protein

Granule-associated protein

64 Glutathione reductase (EC 1.8.1.7)

2 Universal stress protein family

\section{Virulence, disease, and defense}

87/88 SSU ribosomal protein S1p

\section{Others}

113 Large exoproteins involved in heme utilization or adhesion

81 Response regulator containing CheY-like receiver

Hypothetical protein

1-deoxy-D-xylulose 5-phosphate synthase (EC 2.2.1.7)

gi|53720595

K11065

BPSL2987

gi|5371970

gi|53720358

gi|53719908

gi|53717938

gi|53720836

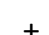

$+$

$+$

K03386

/

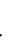

gi|53720125

$+$

K02945

BPSL2515

\begin{tabular}{|c|c|c|c|c|}
\hline gi|53721238 & & + & / & BPSS0203 \\
\hline gi|217424183 & + & & / & BPSS2249 \\
\hline gi|53721449 & + & & / & BPSS0411 \\
\hline gi|53722783 & & + & K01662 & BPSS1762 \\
\hline
\end{tabular}

$261{ }^{a}$ Immunogenic protein position corresponding to spot on gel (Figure 1).

$262{ }^{b}$ KEGG stands for Kyoto Encyclopedia of Genes and Genomes.

$263{ }^{C}$ EC (Enzyme Commission number) means a numerical classification for enzymes according to their catalysis reaction. 
Table 3. Percent identity of immunogenic proteins of B. pseudomallei compared to four commensal bacteria and Burkholderia mallei 266 and Burkholderia thailandensis E264.

\begin{tabular}{|c|c|c|c|c|c|c|c|c|}
\hline \multirow{2}{*}{ Species } & \multicolumn{8}{|c|}{ \% Identity of Burkholderia pseudomallei antigenic proteins relative to other bacteria } \\
\hline & GroEL & EF-Tu & Eno & AhpC & $\mathrm{Ndh}$ & FtsA & AtoC & LTTR \\
\hline Staphylococcus aureus NCTC8325 (taxid:93061) & $58 \%$ & $77 \%$ & $64 \%$ & $28 \%$ & $25 \%$ & NS & NS & $21 \%$ \\
\hline Clostridium perfringens F262 (taxid:883064) & $60 \%$ & $75 \%$ & $65 \%$ & $32 \%$ & NS * & $27 \%$ & $41 \%$ & NS \\
\hline Lactobacillus acidophilus ATCC 4796 (taxid:525306) & $58 \%$ & $26 \%$ & $51 \%$ & $33 \%$ & $24 \%$ & $26 \%$ & NS & NS \\
\hline Escherichia coli MG1655 (taxid:511145) & $76 \%$ & $80 \%$ & $66 \%$ & $33 \%$ & $45 \%$ & $47 \%$ & $46 \%$ & $30 \%$ \\
\hline Burkholderia mallei ATCC 23344 (taxid:243160) & $99 \%$ & $100 \%$ & $100 \%$ & $100 \%$ & $100 \%$ & $99 \%$ & $99 \%$ & $99 \%$ \\
\hline Burkholderia thailandensis E264 (taxid:271848) & $99 \%$ & $100 \%$ & $99 \%$ & $100 \%$ & $93 \%$ & $99 \%$ & $94 \%$ & $99 \%$ \\
\hline
\end{tabular}

* NS: No Significant Similarity

268 (A) Heat shock protein 60 family chaperone, GroEL (B) Translation elongation factor Tu, EF-Tu (C) Enolase, Eno (D) Alkyl hydroperoxide reductase subunit C, AhpC (E) NADH dehydrogenase, Ndh (F) Cell division protein, FtsA (G) Sigma-54 dependent DNA binding response regulator, AtoC (H) LysR family transcriptional regulator, LTTR. 


\section{Discussion}

\section{Immunogenic protein profiles}

Our findings demonstrate common and unique immunogenic proteins across the four $B$. pseudomallei strains from different melioidosis cases. Given the different clinical presentations and time courses of infection and disease for each serum collection, it is to be expected that the primary immunogenic proteins would vary across the matched four strain sera [29]. It has been postulated that variation in immunogenic proteins can be related to different stages of illness and the different clinical presentation's related to particular virulence pathways.

We identified 50 immunogenic proteins from 135 total immunogenic protein spots by MS. Most proteins identified in this study had not been previously described as immunogenic in B. pseudomallei, but six had been identified as immunogenic outer membrane proteins by Harding et al. [30] and seven proteins detected in this study were found by Felgner et al. [14] . These proteins are GroEL, AtpD, AtpA, DnaK, EF-Tu, AphC, FliC, and sucrose-6-phosphate hydrolase. Most previous studies have used pooled sera and then investigated whole cell lysate samples, fractionated proteins, or preselected immunogenic recombinant protein candidates [14, 31-33]. We detected fewer immunogenic proteins when compared to other studies. Our use of whole cell lysates may be a limiting factor that prevents us from detecting the immunogenicity of low concentration proteins. However it also allows us to determine the relative protein abundance and identify highly immunogenic proteins. Analyzing each strain with only one serum time-point from each patient may restrict our ability to detect additional immunogenic proteins as the patterns may change as the disease progresses. There are eight common immunogenic proteins observed across all four strain x serum combinations. 


\section{Chaperone GroEL}

Of the identified immunogenic proteins, heat-shock proteins (hsps) were detected with great intensity and seroreactivity. Woo et al. [31] showed that sera from melioidosis patients showed a stronger antigen-antibody response to heat-shock protein 60 family chaperone GroEL than sera from patients infected with Burkholderia cepacia complex strains. Amemiya et al. [32] also found that GroEL was far more immunoreactive than DnaK. From this, it is not surprising that GroEL is a dominant immunogenic protein. Varga and colleagues [34] also found that the antibodies against GroEL increased almost 5 fold after infection [34]. B. pseudomallei has two copies of GroEL (BPSL2697 and BPSS0477) with 83\% sequence identity. Only GroEL1 (BPSL2697) was detected in this study.

As a Hsp, GroEL is known to be involved in assisting protein folding in vivo. This folding process is subjected to interference from elevated temperatures, changing $\mathrm{pH}$, and oxidative stress. Given the high conservation of hsps, particularly among related bacteria, it is possible that the host immune system is "primed" to target common epitopes of hsps, particularly GroEL, explaining its high seroreactivity with melioidosis. This idea is consistent with the work of Yamaguchi et al. [35], who found an epitope on Helicobacter pylori GroEL that was shared with numerous other species.

\section{Alkyl Hydroperoxide Reductase Protein C}

Free radicals and oxidative stress play important roles in the innate immune response of the host. Phagocytic cells are able to kill invading bacteria through a pathway reliant on reactive oxygen and nitrogen intermediates [36]. Two of these roles are to inhibit proteases via Snitrosylation of the cysteine residues in the activation site and nicking of DNA to induce apoptosis [36-39]. In this study, AhpC (Akyl hydroperoxide reductase protein C), a predicted 
oxidative stress response protein was detected in all four strains. As AhpC was highly expressed, it is possible that the expression of this protein is up-regulated during the early stages of infection and phagocytosis when oxidative stress response is at its greatest in the host $[36,40]$. If this postulate is correct, then AhpC may represent an attractive target for early immunological diagnosis of melioidosis.

\section{Enolase}

The main function of enolase is a part of the glycolysis pathway, but it has also been described as a "moonlighting" protein, detected on the cell surface and involved in plasminogen binding. This additional function allows the bacteria to penetrate the extracellular matrix and cell membrane, facilitating the spread of bacteria into tissue. Enolases do not have traditional sorting signals and it is unknown how the proteins are transferred to the cell surface [41-43].

The amino acid sequence of enolase in B. pseudomallei (BPSL2270) is rich in alanine, glycine, and leucine $(11 \%, 10.8 \%$, and $10.1 \%$, respectively). Lysine is recognized as an important amino acid in the active site of the C-terminus and comprises $4.7 \%$ of the sequence in BPSL2270. A hydrophobic domain and posttranslational acylation or phosphorylation are known to play a role in membrane association [41].

Folden et al. [44] found that Borrelia burgdorferi enolase was exposed on the cell surface using microscopy and immunoassays and acted as a receptor for plasminogen. They also examined the conversion of plasminogen to plasmin and immunoblotted enolases of recombinant and cell lysates. These enolases proven to be strongly seropositive are consistent with our results.

\section{Elongation Factor Tu}


Translational elongation factor $\mathrm{Tu}(\mathrm{EF}-\mathrm{Tu})$ contributes to the lengthening of the peptide chain in protein synthesis $[45,46]$, but has additionally been reported as an adhesin, necessary for cell invasion in several pathogenic bacteria. Nieve et al. [47] identified AhpC, DnaK, and EF-Tu as highly immunogenic proteins of the closely related Burkholderia thailandensis. They found that intranasal immunization using a recombinant EF-Tu was able to generate an IgG antibody that recognized the native EF-Tu, representing a potential vaccine target for $B$. pseudomallei.

Granto et al. [48] identified EF-Tu in Lactobacillus johnsonii NCC533 (La1) as immunogenic surface molecules which mediated attachment to intestinal epithelial cells and mucins. Kolberg et al. [49] also found EF-Tu to be surface exposed in multiple bacteria using flow cytometry. It appears that EF-Tu is highly immunogenic in multiple species and plays a critical role for pathogens in invasion of host cells.

\section{LysR family transcriptional regulator}

LTTRs are one of the most abundant types of transcriptional regulators in known in prokaryotics[50]. These proteins regulate diverse genes involved in virulence, metabolism, and motility. Rainbow et al. (2002) report that the proteins of the LysR family possess a potential 'helix-turn-helix' DNA-binding motif that is conserved in their N-terminal section.

\section{Sigma-54 dependent DNA binding response regulator}

AtoC are regulators responsive to a variety of environmental signals. Chemical and metabolic changes modulate the expression or the activity of regulatory proteins for determining the level of expression of sigma54-dependent genes and hence the diverse bacterial functions 
that they encode. Sigma-54 proteins are widespread among bacteria and required for diverse functions such as motility, phage shock response, and nitrogen assimilation (Reitzer, 2003) Immunogenic variable proteins

Most of the immunogenic proteins are specific to serum and strain. For examples, AtpD, AtpA, DnaK, flagellum (FliC), and sucrose-6-phosphate hydrolase are common immunogenic proteins identified previously by Felgner et al. [14], but our study has shown that they are detected in not all cases. It is postulated that the variation in detected immunogenic proteins can be caused by different stages of illness and also that the different clinical presentation reflects different pathways of virulent protein involvement [29].

Gene expression studies have shown that ATP synthases such as AtpA and AtpD can be down-regulated. In host-pathogen interactions, the bacteria in the intracellular state adjust nutrient availability for survival, resulting in down regulation of energy metabolism such as ATP synthase and NADH dehydrogenase [51]. Tuanyok et al. [52] found that iron stress results in modulation of expression of ATP synthase subunit epsilon. But this research found strong reactivity for ATP. It is postulated that the proteins are required for surviving and thriving in the host.

FliC protein is believed to play roles of motility of the bacterium to disseminate from localized sites, such as skin and lung, to other organs via bacteremic spread. This ability of $B$. pseudomallei may be important also for intracellular survival and in the pathogenicity of both acute and chronic infection [53]. Chua et al. [54] constructed isogenic deletion mutant with flagellum gene (fliC) and challenged mice with the mutant; all animals infected with this mutant remained healthy. The patient whose serum linked to B. pseudomallei PB1007001 presented with a skin abscess and associated swollen regional lymph node. This illness followed a presumptive 
inoculating skin cut on the leg. From this patient serum, FliC was detected as an immunogenic protein.

DnaK is a chaperone protein having conserved domain like GroEL, which remains unchanged level at different media and surrounding environment and keep the transcript level even in different strains [55]. That means this chaperone protein had the sample transcript level across all the four stains at this research. At this research, two sera showed reactivity to DnaK. This protein was also identified as being immunoreactive with melioidosis case sera by others $[14,30]$. Being detected by only two isolates out of four may reflect different pathway of infection or progress of infection.

\section{Comparison of identified common immunogenic protein sequence}

We blasted our commonly detected immunogenic protein sequences with those of selected commensal bacteria, B. mallei and B. thailandensis strains to investigate structural similarities. Most of our common immunogenic proteins are chaperonins, which have highly conserved structure. Those conserved structures have high similarity with commensal bacteria and other genetically similar species. This could hinder these proteins from being used as a specific biomarkers for diagnosis or as vaccine target. Vaccine candidates should be differentiated between beneficial and harmful microbes.

The sequence comparison of the common proteins showed that the similarities were lower with commensal bacteria. These are of greatest concern as they can colonize healthy humans and are distributed widely. The lower similarities imply that the identified 8 proteins might be useful as vaccine candidates and would not cause an immune reaction to commensal microbes. The common proteins of $B$. pseudomallei matched or were very high similarity to $B$. 
mallei and B. thailandensis. However, Ndh and AtoC of B. pseudomallei showed the slightly lower similarity with potential as a diagnosis biomarker.

Translating our proteome data to other proteome studies of B. pseudomallei recovered from different clinical presentations and to serial sera responses over the time course of infections of individual patients will help further unravel the pathogenesis of infection with $B$. pseudomallei.

\section{Conclusion}

We identified proteins common to all four strains that are strongly immunogenic with all sera used. Perhaps not coincidentally, these proteins are also highly expressed as visualized with 2DE and silver staining. This suggests that this group of eight known proteins have a potential for use as diagnostic targets or vaccine subunits. Further studies of more patient-B. pseudomallei isolate matches are required to assess the universality of these protein responses and to also determine how the progression of disease affects the expression of B. pseudomallei proteins and the resulting host antibody production.

\section{Acknowledgement.}

This work was supported by the United States Department of Homeland Security (https://www.dhs.gov/) grant no. HSHQDC-10-C-00135 and Defense Threat Reduction Agency (http://www.dtra.mil/) grant no. HDTRA1-12-C-0022. We thank our laboratory colleagues at the Royal Darwin Hospital for their support and expertise in diagnosis of melioidosis and 
bioRxiv preprint doi: https://doi.org/10.1101/082057; this version posted November 20, 2016. The copyright holder for this preprint (which was not certified by peer review) is the author/funder. All rights reserved. No reuse allowed without permission.

identification of B. pseudomallei, and Vanessa Theobald and Glenda Harrington at the Menzies

School of Health Research for laboratory assistance with this study. 


\section{Reference}

1. Cheng AC, Currie BJ. Melioidosis: Epidemiology, pathophysiology, and management. Clin Microbiol Rev. 2005;18(2):383-416. doi: 10.1128/cmr.18.2.383-416.2005. PubMed PMID: ISI:000228543300006.

2. Limmathurotsakul D, Golding N, Dance DA, Messina JP, Pigott DM, Moyes CL, et al. Predicted global distribution of and burden of melioidosis. Nature microbiology. 2016;1(1). Epub 2016/02/16. doi: 10.1038/nmicrobiol.2015.8. PubMed PMID: 26877885; PubMed Central PMCID: PMC4746747.

3. Currie B, Dance D, Cheng A. The global distribution of Burkholderia pseudomallei and melioidosis: an update. Trans R Soc Trop Med Hyg. 2008;102(Suppl 1):S1 - S4. Epub 2009/01/16. doi: 10.1016/S0035-9203(08)70002-6. PubMed PMID: 19121666.

4. Wiersinga WJ, Currie BJ, Peacock SJ. Melioidosis. N Engl J Med. 2012;367(11):103544.

5. Limmathurotsakul D, Chaowagul W, Chierakul W, Stepniewska K, Maharjan B, Wuthiekanun V, et al. Risk factors for recurrent melioidosis in northeast Thailand. Clin Infect Dis. 2006;43(8):979-86. doi: 10.1086/507632. PubMed PMID: WOS:000240666200005.

6. Sarovich DS, Price EP, Limmathurotsakul D, Cook JM, Von Schulze AT, Wolken SR, et al. Development of ceftazidime resistance in an acute Burkholderia pseudomallei infection. Infect Drug Resist. 2012;5:129-32.

7. Chantratita N, Rholl DA, Sim B, Wuthiekanun V, Limmathurotsakul D, Amornchai P, et al. Antimicrobial resistance to ceftazidime involving loss of penicillin-binding protein 3 in Burkholderia pseudomallei. Proceedings of the National Academy of Sciences.

2011;108(41):17165-70. doi: 10.1073/pnas.1111020108.

8. Schweizer HP. Mechanisms of antibiotic resistance in Burkholderia pseudomallei: implications for treatment of melioidosis. Future Microbiol. 2012;7(12):1389-99. doi: 10.2217/fmb.12.116. PubMed PMID: WOS:000312474400011.

9. White NJ. Melioidosis. The Lancet. 2003;361(9370):1715-22. doi: 10.1016/s01406736(03)13374-0.

10. Burtnick MN, Brett PJ, Harding SV, Ngugi SA, Ribot WJ, Chantratita N, et al. The Cluster 1 Type VI Secretion System Is a Major Virulence Determinant in Burkholderia pseudomallei. Infect Immun. 2011;79(4):1512-25. doi: 10.1128/iai.01218-10. PubMed PMID: WOS:000288532300013.

11. Galan JE, Collmer A. Type III secretion machines: Bacterial devices for protein delivery into host cells. Science. 1999;284(5418):1322-8. doi: 10.1126/science.284.5418.1322. PubMed PMID: WOS:000080430600044.

12. Stevens MP, Wood MW, Taylor LA, Monaghan P, Hawes P, Jones PW, et al. An Inv/Mxi-Spa-like type III protein secretion system in Burkholderia pseudomallei modulates intracellular behaviour of the pathogen. Mol Microbiol. 2002;46(3):649-59. doi: 10.1046/j.13652958.2002.03190.x.

13. Wolfe DN, Florence W, Paula B. Current biodefense vaccine programs and challenges. Human Vaccines \& Immunotherapeutics. 2013;9(7):1591-7.

14. Felgner PL, Kayala MA, Vigil A, Burk C, Nakajima-Sasaki R, Pablo J, et al. A Burkholderia pseudomallei protein microarray reveals serodiagnostic and cross-reactive 
antigens. Proc Natl Acad Sci U S A. 2009;106(32):13499-504. doi: 10.1073/pnas.0812080106. PubMed PMID: ISI:000268877300064.

15. Tuanyok A, Stone JK, Mayo M, Kaestli M, Gruendike J, Georgia S, et al. The genetic and molecular basis of O-antigenic diversity in Burkholderia pseudomallei lipopolysaccharide. PLoS neglected tropical diseases. 2012;6(1):e1453. Epub 2012/01/12. doi: 10.1371/journal.pntd.0001453. PubMed PMID: 22235357; PubMed Central PMCID: PMC3250505.

16. Stewart T, Engelthaler DM, Blaney DD, Tuanyok A, Wangsness E, Smith TL, et al. Epidemiology and investigation of melioidosis, Southern Arizona. Emerging infectious diseases. 2011;17(7):1286-8. Epub 2011/07/19. doi: 10.3201/eid1707.100661. PubMed PMID: 21762589; PubMed Central PMCID: PMC3381374.

17. Bradford MM. A rapid and sensitive method for the quantitation of microgram quantities of protein utilizing the principle of protein-dye binding. Analytical Biochemistry. 1976;72(12):248-54.

18. Ofarrell PH. HIGH-RESOLUTION 2-DIMENSIONAL ELECTROPHORESIS OF PROTEINS. J Biol Chem. 1975;250(10):4007-21. PubMed PMID: ISI:A1975AD05500064.

19. Rabilloud T, Adessi C, Giraudel A, Lunardi J. Improvement of the solubilization of proteins in two-dimensional electrophoresis with immobilized $\mathrm{pH}$ gradients. Electrophoresis. 1997;18(3-4):307-16. doi: 10.1002/elps.1150180303. PubMed PMID: WOS:A1997WW35800002.

20. Gorg A, Weiss W, Dunn MJ. Current two-dimensional electrophoresis technology for proteomics. Proteomics. 2004;4(12):3665-85. PubMed PMID: ISI:000225801200001.

21. Shevchenko A, Wilm M, Vorm O, Mann M. Mass Spectrometric Sequencing of Proteins from Silver-Stained Polyacrylamide Gels. Analytical Chemistry. 1996;68(5):850-8. doi: 10.1021/ac950914h.

22. Shevchenko A, Tomas H, Havlis J, Olsen JV, Mann M. In-gel digestion for mass spectrometric characterization of proteins and proteomes. Nat Protocols. 2007;1(6):2856-60.

23. Shilov IV, Seymour SL, Patel AA, Loboda A, Tang WH, Keating SP, et al. The paragon algorithm, a next generation search engine that uses sequence temperature values and feature probabilities to identify peptides from tandem mass spectra. Mol Cell Proteomics. 2007;6(9):1638-55. doi: 10.1074/mcp.T600050-MCP200. PubMed PMID: WOS:000249237200014.

24. Aziz RK, Bartels D, Best AA, DeJongh M, Disz T, Edwards RA, et al. The RAST server: Rapid annotations using subsystems technology. BMC Genomics. 2008;9. doi: 10.1186/14712164-9-75. PubMed PMID: WOS:000253988600002.

25. Meyer F, Overbeek R, Rodriguez A. FIGfams: yet another set of protein families. Nucleic Acids Res. 2009;37(20):6643-54. doi: 10.1093/nar/gkp698. PubMed PMID: WOS:000271819900001.

26. Yu NY, Laird MR, Spencer C, Brinkman FSL. PSORTdb-an expanded, auto-updated, user-friendly protein subcellular localization database for Bacteria and Archaea. Nucleic Acids Res. 2011;39:D241-D4. doi: 10.1093/nar/gkq1093. PubMed PMID: ISI:000285831700041. 27. Petersen TN, Brunak S, von Heijne G, Nielsen H. SignalP 4.0: discriminating signal peptides from transmembrane regions. Nat Methods. 2011;8(10):785-6. doi: 10.1038/nmeth.1701. PubMed PMID: WOS:000295358000004. 
28. Pearson T, Giffard P, Beckstrom-Sternberg S, Auerbach R, Hornstra H, Tuanyok A, et al. Phylogeographic reconstruction of a bacterial species with high levels of lateral gene transfer. BMC biology. 2009;7(1):78.

29. Sarovich DS, Price EP, Webb JR, Ward LM, Voutsinos MY, Tuanyok A, et al. Variable Virulence Factors in Burkholderia pseudomallei (Melioidosis) Associated with Human Disease. PLoS One. 2014;9(3). doi: 10.1371/journal.pone.0091682. PubMed PMID: WOS:000332842400118.

30. Harding SV, Sarkar-Tyson M, Smither SJ, Atkins TP, Oyston PCF, Brown KA, et al. The identification of surface proteins of Burkholderia pseudomallei. Vaccine. 2007;25(14):2664-72. doi: 10.1016/j.vaccine.2006.12.006. PubMed PMID: ISI:000245732700016.

31. Woo PCY, Leung PKL, Wong SSY, Ho P-L, Yuen K-Y. groEL Encodes a Highly Antigenic Protein in Burkholderia pseudomallei. Clin Diagn Lab Immunol. 2001;8(4):832-6. doi: 10.1128/cdli.8.4.832-836.2001.

32. Amemiya K, Meyers JL, DeShazer D, Riggins RN, Halasohoris S, England M, et al. Detection of the host immune response to Burkholderia mallei heat-shock proteins GroEL and DnaK in a glanders patient and infected mice. Diagn Microbiol Infect Dis. 2007;59(2):137-47. doi: 10.1016/j.diagmicrobio.2007.04.017.

33. Suwannasaen D, Mahawantung J, Chaowagul W, Limmathurotsakul D, Felgner PL, Davies H, et al. Human Immune Responses to Burkholderia pseudomallei Characterized by Protein Microarray Analysis. J Infect Dis. 2011;203(7):1002-11. doi: 10.1093/infdis/jiq142. PubMed PMID: ISI:000288553800016.

34. Varga JJ, Vigil A, DeShazer D, Waag DM, Felgner P, Goldberg JB. Distinct human antibody response to the biological warfare agent Burkholderia mallei. Virulence. 2012;3(6):5104. doi: 10.4161/viru.22056. PubMed PMID: WOS:000312000300007.

35. Yamaguchi H, Osaki T, Taguchi H, Hanawa T, Yamamoto T, Kamiya S. Production and characterisation of monoclonal antibodies to heat-shock protein 60 of Helicobacter pylori.

Journal of Medical Microbiology. 1997;46(10):819-24. PubMed PMID: WOS:A1997YA85800003.

36. Bogdan C, Rollinghoff M, Diefenbach A. Reactive oxygen and reactive nitrogen intermediates in innate and specific immunity. Curr Opin Immunol. 2000;12(1):64-76. doi: 10.1016/s0952-7915(99)00052-7. PubMed PMID: WOS:000085306900009.

37. Stamler JS. S-nitrosothiols and the bioregulatory actions of nitrogen oxides through reactions with thiol groups. Curr Top Microbiol Immunol. 1995;196:19-36. PubMed PMID: MEDLINE:7634823.

38. Keefer LK, Wink DA. DNA damage and nitric oxide. Advances in experimental medicine and biology. 1996;387:177-85. PubMed PMID: MEDLINE:8794210.

39. Loprasert S, Sallabhan R, Whangsuk W, Mongkolsuk S. Compensatory increase in ahpC gene expression and its role in protecting Burkholderia pseudomallei against reactive nitrogen intermediates. Arch Microbiol. 2003;180(6):498-502. doi: 10.1007/s00203-003-0621-9. PubMed PMID: WOS:000187013900015.

40. Adler NRL, Govan B, Cullinane M, Harper M, Adler B, Boyce JD. The molecular and cellular basis of pathogenesis in melioidosis: how does Burkholderia pseudomallei cause disease? Fems Microbiol Rev. 2009;33(6):1079-99. doi: 10.1111/j.1574-6976.2009.00189.x. PubMed PMID: ISI:000270397600004.

41. Pancholi V. Multifunctional alpha-enolase: its role in diseases. Cell Mol Life Sci. 2001;58(7):902-20. doi: 10.1007/p100000910. PubMed PMID: WOS:000170010400005. 
42. Lahteenmaki K, Edelman S, Korhonen TK. Bacterial metastasis: the host plasminogen system in bacterial invasion. Trends Microbiol. 2005;13(2):79-85. doi: 10.1016/j.tim.2004.12.003. PubMed PMID: WOS:000227298600009.

43. Henderson B, Martin A. Bacterial Virulence in the Moonlight: Multitasking Bacterial Moonlighting Proteins Are Virulence Determinants in Infectious Disease. Infect Immun. 2011;79(9):3476-91. doi: 10.1128/iai.00179-11. PubMed PMID: WOS:000293891000001.

44. Floden AM, Watt JA, Brissette CA. Borrelia burgdorferi Enolase Is a Surface-Exposed Plasminogen Binding Protein. PLoS One. 2011;6(11). doi: 10.1371/journal.pone.0027502. PubMed PMID: WOS:000297349700053.

45. Hendrick JP, Hartl FU. MOLECULAR CHAPERONE FUNCTIONS OF HEATSHOCK PROTEINS. Annu Rev Biochem. 1993;62:349-84. doi: 10.1146/annurev.bi.62.070193.002025. PubMed PMID: WOS:A1993LK68700013.

46. Andersen GR, Nissen P, Nyborg J. Elongation factors in protein biosynthesis. Trends BiochemSci. 2003;28(8):434-41. doi: 10.1016/s0968-0004(03)00162-2.

47. Nieves W, Heang J, Asakrah S, Bentrup KHZ, Roy CJ, Morici LA. Immunospecific Responses to Bacterial Elongation Factor Tu during Burkholderia Infection and Immunization. PLoS One. 2010;5(12):12. doi: e14361

10.1371/journal.pone.0014361. PubMed PMID: ISI:000285572900004.

48. Granato D, Bergonzelli GE, Pridmore RD, Marvin L, Rouvet M, Corthesy-Theulaz IE. Cell surface-associated elongation factor Tu mediates the attachment of Lactobacillus johnsonii NCC533 (La1) to human intestinal cells and mucins. Infect Immun. 2004;72(4):2160-9. doi: 10.1128/iai.72.4.2160-2169.2004. PubMed PMID: WOS:000220481600037.

49. Kolberg J, Hammerschmidt S, Frank R, Jonak J, Sanderova H, Aase A. The surfaceassociated elongation factor $\mathrm{Tu}$ is concealed for antibody binding on viable pneumococci and meningococci. FEMS Immunol Med Microbiol. 2008;53(2):222-30. doi: 10.1111/j.1574695X.2008.00419.x. PubMed PMID: WOS:000256717800010.

50. Schell MA. MOLECULAR-BIOLOGY OF THE LYSR FAMILY OF TRANSCRIPTIONAL REGULATORS. Annu Rev Microbiol. 1993;47:597-626. doi: 10.1146/annurev.micro.47.1.597. PubMed PMID: WOS:A1993MA27600021.

51. Chieng S, Carreto L, Nathan S. Burkholderia pseudomallei transcriptional adaptation in macrophages. BMC Genomics. 2012;13(328):1471-2164.

52. Festa F, Steel J, Bian XF, Labaer J. High-throughput cloning and expression library creation for functional proteomics. Proteomics. 2013;13(9):1381-99. doi: 10.1002/pmic.201200456. PubMed PMID: WOS:000318049800002.

53. Kespichayawattana W, Rattanachetkul S, Wanun T, Utaisincharoen P, Sirisinha S. Burkholderia pseudomallei induces cell fusion and actin-associated membrane protrusion: a possible mechanism for cell-to-cell spreading. Infect Immun. 2000;68(9):5377-84. doi: 10.1128/iai.68.9.5377-5384.2000. PubMed PMID: WOS:000088870200073.

54. Chua KL, Chan YY, Gan YH. Flagella are virulence determinants of Burkholderia pseudomallei. Infect Immun. 2003;71(4):1622-9. doi: 10.1128/iai.71.4.1622-1629.2003. PubMed PMID: WOS:000181926200002.

55. Burtnick MN, Brett PJ. Burkholderia mallei and Burkholderia pseudomallei Cluster 1 Type VI Secretion System Gene Expression Is Negatively Regulated by Iron and Zinc. PLoS One. 2013;8(10):11. doi: 10.1371/journal.pone.0076767. PubMed PMID: WOS:000325819400081. 
bioRxiv preprint doi: https://doi.org/10.1101/082057; this version posted November 20, 2016. The copyright holder for this preprint (which was not certified by peer review) is the author/funder. All rights reserved. No reuse allowed without permission. 


\section{FIGURES AND TABLES}

Figure 1: 2D silver stained map of immunogenic proteins of four Burkholderia pseudomallei strains. Colored circles highlight all immunogenic proteins identified. Proteins identified in at least two strains as immunogenic are colored in yellow and in only one strain as follows: MSHR1079 (blue), MSHR1328 (orange), PB08298010 (purple), and PB1007001 (green).

Figure 2: Comparison of immunogenic proteins identified from four Burkholderia pseudomallei strains. Number is the total detected immunogenic protein spots for each strain and numbers in parentheses are the number of identified immunogenic protein spots for each strain by mass spectrometry. Colored circles correspond to each strain as follows: MSHR1079 (blue), MSHR1328 (orange), PB08298010 (purple), and PB1007001 (green). Note: This 2DE image was generated from B. pseudomallei strain PB0829010.

Table 1: Summary of Burkholderia pseudomallei strains and human patient serum used in this study.

Table 2: Immunogenic proteins identified from four Burkholderia pseudomallei strains

a Immunogenic protein position corresponding to spot on gel (Figure 1).

${ }^{b}$ KEGG stands for Kyoto Encyclopedia of Genes and Genomes.

${ }^{\mathrm{C}}$ EC (Enzyme Commission number) means a numerical classification for enzymes according to their catalysis reaction.

Table 3: Percent identity of immunogenic proteins of B. pseudomallei compared to four commensal bacteria and Burkholderia mallei and Burkholderia thailandensis E264.

* NS: No Significant Similarity

(A) Heat shock protein 60 family chaperone, GroEL (B) Translation elongation factor Tu, EF-Tu (C) Enolase, Eno (D) Alkyl hydroperoxide reductase subunit C, AhpC (E) NADH dehydrogenase, Ndh (F) Cell division protein, FtsA (G) Sigma-54 dependent DNA binding response regulator, AtoC (H) LysR family transcriptional regulator, LTTR. 


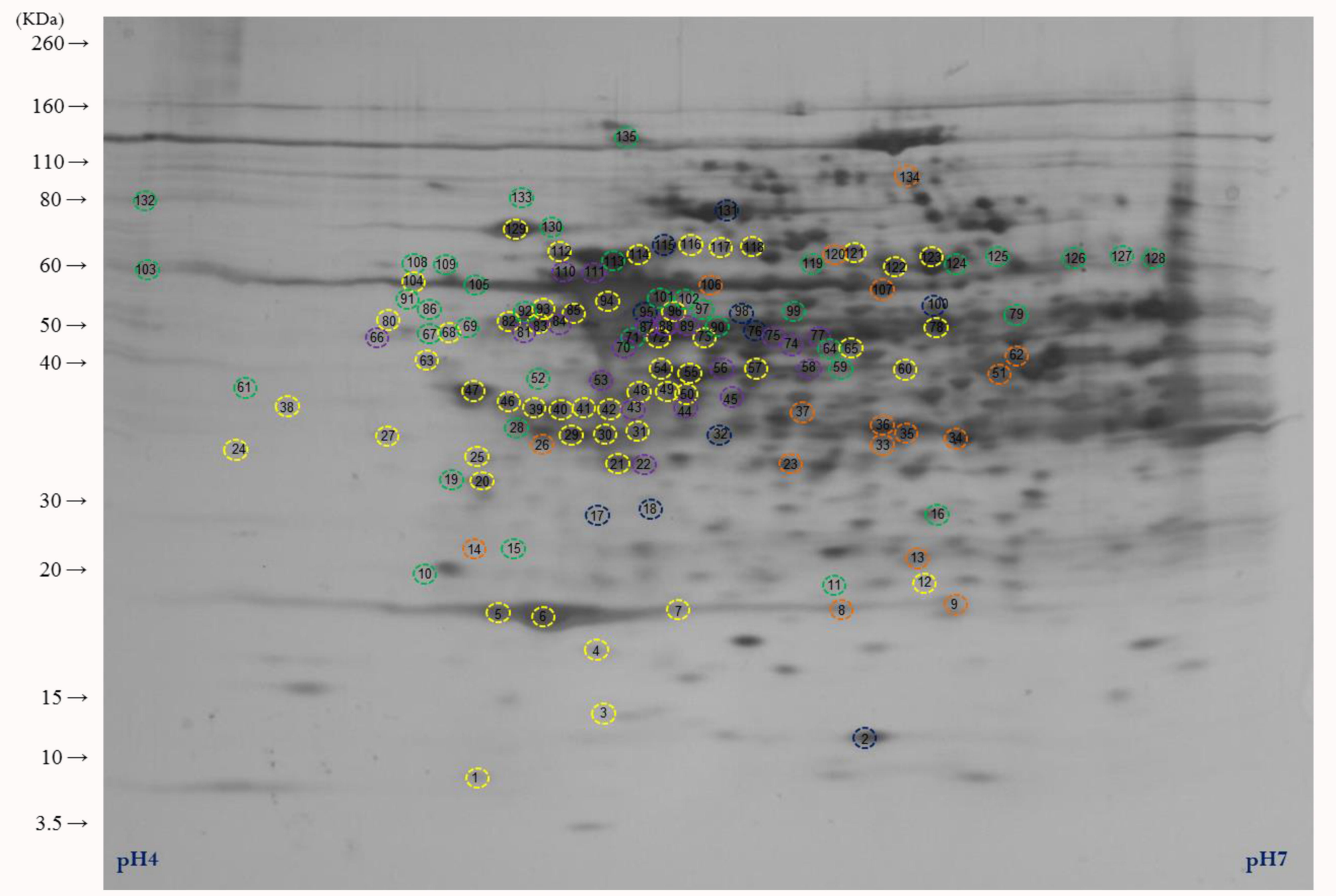


